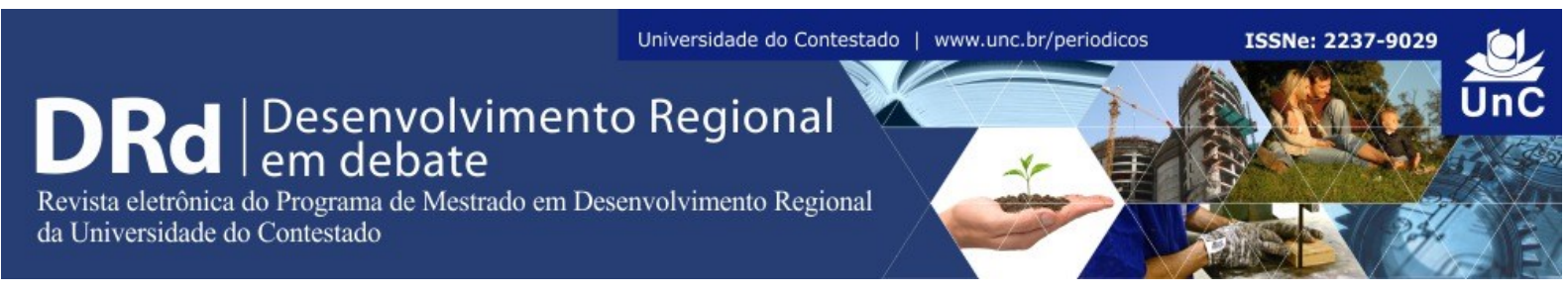

\title{
GERENCIAMENTO COSTEIRO INTEGRADO NO BRASIL: UMA ANÁLISE QUALITATIVA DO PLANO NACIONAL DE GERENCIAMENTO COSTEIRO
}

\author{
Juliana da Silva Ibiapina Cavalcante ${ }^{1}$ \\ Magdi Ahmed Ibrahim Aloufa ${ }^{2}$
}

\begin{abstract}
RESUMO
As zonas costeiras representam um grande desafio para a gestão brasileira por apresentarem inúmeras pressões socioeconômicas e por serem áreas com grande densidade populacional, caracterizada por dinâmicas peculiares. Sendo assim, como forma de orientar a utilização racional dos recursos da zona costeira, visando contribuir para elevar a qualidade de vida de sua população, e a proteção de seu patrimônio natural, histórico, étnico e cultural, o Brasil, através da Lei $\mathrm{n}^{\mathrm{0}} 7.661$ de 1988, instituiu o Plano Nacional de Gerenciamento Costeiro PNGC. O objetivo desta pesquisa é verificar a situação da zona costeira brasileira desde a instituição do PNGC, apontando as potencialidades, problemáticas, carências, bem como órgãos e instituições envolvidas com a gestão costeira. Para tanto, foi realizada uma análise documental do relatório " 25 anos do Gerenciamento Costeiro no Brasil" que passou por fases específicas da investigação qualitativa, a saber: fase de leituras flutuantes; desmontagem dos textos e seleção das unidades de análise; categorização, e; captação da compreensão emergente. A análise contribuiu para uma reflexão sobre os principais desafios e expectativas enfrentadas pela gestão costeira em todo o território nacional. Constatou-se, ainda, que muitas atividades em plena expansão, contribuem para o desenvolvimento econômico do país, entretanto, trazem consigo inúmeros impactos. Assim, tem sido um desafio compatibilizar as atividades e a sustentabilidade das regiões. Para tanto, vem sendo desenvolvida a Gestão Costeira, trazendo instrumentos legais, planos, programas e projetos, o que têm trazido resultados positivos em direção ao gerenciamento dos usos das zonas litorâneas, com vistas à mitigação de inúmeros impactos, evitando prejuízos de diversas ordens. Porém, há ainda carências na gestão costeira que deverão ser sanadas para a promoção do ordenamento do uso dos recursos naturais e da ocupação dos espaços costeiros.
\end{abstract}

Palavras-chave: Zonas litorâneas. Políticas Públicas. Gerenciamento Costeiro. Impactos. Análise documental.

\footnotetext{
${ }^{1}$ Mestre em Desenvolvimento e Meio Ambiente (UFRN). Professora, Instituto Federal de Educação, Ciência e Tecnologia do Rio Grande do Norte (IFRN), Campus Mossoró, Coordenação de Tecnologia em Gestão Ambiental. Mossoró. Rio Grande do Norte. Brasil. E-mail: juliana.ibiapina@hotmail.com

${ }^{2}$ Doutor em Biologia e Fisiologia Vegetal (Université Pierre et Marie Curie). Professor, Universidade Federal do Rio Grande do Norte (UFRN), Departamento de Botânica, Ecologia e Zoologia. Natal. Rio Grande do Norte. Brasil. E-mail: magdialoufal@gmail.com
} 


\title{
COASTAL MANAGEMENT INTEGRATED IN BRAZIL: A QUALITATIVE ANALYSIS OF NATIONAL COASTAL MANAGEMENT PLAN
}

\begin{abstract}
Coastal areas represent a major challenge for the Brazilian management. In the coastal region are numerous socio-economic pressures, especially for being an area with high population density, characterized by peculiar dynamics. Thus, in order to guide the rational use of resources of the coastal zone, in order to contribute to raise the population quality of life, and the protection of their natural heritage, historical, ethnic and cultural, Brazil, through Law $\mathrm{N}^{\circ}$. 7.661/1988 established the National Coastal Management Plan. The objective of this research is to verify the situation of the Brazilian coastal zone since the institutionalization of the National Coastal Management Plan, pointing out the potentialities, problems, shortcomings, as well as the organisms and institutions involved with the coastal management. In order to do so, a documentary analysis of the report "25 years of Coastal Management in Brazil" was carried through specific phases of qualitative research, namely: floating readings phase; disassembly of texts and selection of analysis units; categorization, and; of emerging understanding. The extracted categories of documentary sample were: Economic activities developed in coastal areas; Main impacts in the Brazilian coastal areas; Instruments for Coastal Management in Brazil; Institutions involved in coastal management in Brazil; main deficiencies of the Brazilian coastal region. The analysis of the documents contributed to a reflection on the main challenges and expectations faced by coastal management throughout the national territory. It was found also that the activities in these areas, many of them in full expansion, contribute to the economic development of the country, however, bring with them numerous impacts inherent to the activities. In this case, the challenges have been to reconcile the activities and sustainability of the regions. Therefore, they have been developed and implemented some actions of the government making up the Management of Coastal Areas. The legal instruments, plans, programs and projects developed have brought positive results towards the management of coastal areas of use, in order to mitigate many impacts, avoiding losses of several orders. However, there are still shortcomings in coastal management which should be addressed to promote land-use of natural resources and occupation of coastal areas.
\end{abstract}

Keywords: Coastal areas. Public policy. Coastal Management. Impacts. Document analysis.

\section{INTRODUÇÃO}

As zonas costeiras representam um grande desafio para a gestão brasileira. A costa litorânea do Brasil compreende uma faixa de $8.698 \mathrm{~km}$ de extensão, incluindo 17 estados e cerca de 400 municípios, onde vivem cerca de $25 \%$ da população brasileira (MMA, 2008).

Neste ambiente, portanto, a paisagem é regulada por dinâmicas peculiares e pela interrelação entre o meio físico-biológico e o socioeconômico (OLIVEIRA, 2008). Além disso, inúmeras são as pressões socioeconômicas na zona costeira, podendo-se destacar o acelerado e desordenado processo de urbanização acarretando a intensa degradação dos recursos naturais, colocando em xeque a sustentabilidade socioeconômica e a qualidade ambiental das populações (SOUZA, 2009). 
Como forma de contribuir com a gestão das zonas costeiras e lidar, por exemplo, com os impactos da ocupação urbana e demais atividades antrópicas, alguns organismos internacionais, vêm exigindo ações preventivas em face da possibilidade de esgotamento dos recursos nesses ambientes tão sensíveis de imensurável importância (GRUBER; BARBOZA; NICOLODI, 2003). São eles: ONU (Organização das Nações Unidas), OEA (Organização dos Estados Americanos), COI (Comissão Oceanográfica Intergovernamental - UNESCO), SCOR (Comitê Científico para Pesquisas Oceânicas), dentre outros, todos preocupados com os efeitos do desenvolvimento desenfreado e sua interferência para o equilíbrio dos ecossistemas.

Em consonância com o cenário internacional, o arcabouço legal brasileiro apresenta alguns importantes instrumentos. Inicialmente, a Gestão Integrada da Zona Costeira no Brasil foi incorporada através do Programa Nacional de Gerenciamento Costeiro (GERCO), formulado pela Comissão Interministerial para os Recursos do Mar (CIRM) em 1987, com o objetivo de lançar as bases para as ações de planejamento e gestão integrada, descentralizada e participativa da zona costeira (SOUZA, 2009). A constituição brasileira de 1988 destacou, em seu art. 225, a zona costeira como um "patrimônio nacional", caracterizando a região como de interesse especial para a União. Ainda em 1988, instituiu-se a lei no 7.661(Plano Nacional de Gerenciamento Costeiro - PNGC), o qual tem por finalidade "orientar a utilização racional dos recursos da zona costeira, de forma a contribuir para elevar a qualidade de vida de sua população, e a proteção de seu patrimônio natural, histórico, étnico e cultural".

Em nível de estados há, ainda, o Plano Estadual de Gerenciamento Costeiro (PEGC). Estes planos são desenvolvidos pelos Colegiados Costeiros, grupos de representação do Estado, Município e Sociedade Civil Organizada, cuja função é discutir planos, programas e ações para a Gestão Costeira, ressaltando o processo participativo. As metas e diretrizes estabelecidas nos Planos Estaduais devem ser aplicadas em escala local pelos Planos Municipais de Gerenciamento Costeiro.

Diante disso, após três décadas da institucionalização da gestão costeira integrada no Brasil, torna-se necessário realizar uma investigação dos avanços obtidos até então sobre a temática com o intuito de traçar novas metas e planejar ações referentes aos próximos anos da gestão costeira brasileira. Sendo assim, o objetivo deste artigo foi de verificar a situação da zona costeira brasileira desde a instituição do Plano Nacional de Gerenciamento Costeiro, apontando as potencialidades, problemáticas, carências, bem como órgãos e instituições envolvidas com a gestão costeira no Brasil. Para tanto, foi realizada uma análise documental do relatório "25 anos do Gerenciamento Costeiro no Brasil" lançado no ano de 2013 em comemoração aos 25 anos da instituição do Plano Nacional de Gerenciamento Costeiro no Brasil.

\section{MATERIAIS E MÉTODOS}

Este trabalho trata-se de uma pesquisa documental. Esta modalidade de pesquisa permite investigar determinada problemática por meio do estudo dos documentos, que são produzidos pelo homem e revelam suas impressões, modo de ser e de compreender fatos 
sociais (SILVA et al., 2009). Dessa forma, a análise de conteúdo assume a característica de procedimento técnico e sistemático dessa investigação.

Portanto, a amostra documental selecionada é o documento "25 anos do Gerenciamento Costeiro no Brasil" que passou por fases específicas da investigação qualitativa. A análise de conteúdo realizada nesta pesquisa desenvolveu-se por meio da análise categórica em que os textos são decompostos em unidades temáticas, de acordo com Bardin (2011). A sequência do processo de análise de conteúdo, conforme Moraes (2003) é o seguinte:

- Fase de leituras flutuantes:

Após selecionar-se o corpus textual, procede-se às leituras flutuantes, objetivando apreender de uma forma global as ideias principais e os seus significados gerais e organizar alguns aspectos importantes para as próximas fases da análise.

- Desmontagem dos textos e seleção das unidades de análise:

Nesta fase o texto é fragmentado no sentido de atingir unidades constituintes referentes aos fenômenos estudados. A seleção das unidades de análise segue-se de acordo com um processo dinâmico e indutivo de atenção à mensagem e às significações não aparentes do contexto.

- Processo de categorização:

Estabelecimento de relações entre as unidades para compreensão dos elementos unitários rumo ao entendimento do todo. As categorias podem ser caracterizadas como grandes enunciados que abarcam um número variável de temas, segundo seu grau de intimidade ou proximidade. Elas podem traduzir significados e elaborações importantes que atendam aos objetivos de estudo, criando novos conhecimentos e proporcionando uma visão diferenciada sobre os temas propostos.

- Captação da compreensão emergente.

Resultado final da análise.

As unidades de contexto extraídas da amostra documental foram: 1- Atividades; 2Problemas; 3- Instrumentos de gestão; 4- Instituições; 5- Carências. Sendo assim, seguiu-se à análise, identificando-se, também, as subunidades de contexto (temas específicos dentro de cada unidade). 


\section{REFERENCIAL TEÓRICO}

\subsection{CARACTERÍSTICAS GERAIS DA ZONA COSTEIRA}

A zona costeira brasileira corresponde ao espaço geográfico de interação do ar, do mar e da terra, incluindo seus recursos renováveis e não renováveis, abrangendo uma faixa marítima e uma faixa terrestre (Lei $\mathrm{n}^{\mathrm{o}}$ 7.661/1988) e integra o patrimônio nacional, de acordo com a Constituição Federal de 1988. Apesar dessa relevância, são inúmeras as pressões socioeconômicas sobre a zona costeira, podendo-se destacar o acelerado e desordenado processo de urbanização acarretando a intensa degradação dos recursos naturais, colocando em xeque a sustentabilidade socioeconômica e a qualidade ambiental das populações (SOUZA, 2009). Sobre isso, Granziera (2009) afirma:

O planejamento de um espaço tão disputado para as atividades econômicas e para a instalação de cidades, com valores ambientais tão importantes, enfrenta naturalmente uma situação de conflito. Talvez a zona costeira seja uma das regiões brasileiras em que o princípio do desenvolvimento sustentável encontre maiores dificuldades em ser aplicado (GRANZIERA, 2009).

Fernandes (2012, p. 303) também aponta outros fatores como causas da degradação ambiental costeira como, por exemplo, "a especulação imobiliária, loteamentos irregulares, turismo predatório, assentamentos clandestinos, entre outros". É por esta região, inclusive, que as riquezas brasileiras são escoadas, através de estradas e portos, bem como muitas atividades econômicas são desenvolvidas, destacando-se a atividade pesqueira, a extração de petróleo e gás, polos petroquímicos e usinas nucleares - Angra 1 e 2 (GRANZIERA, 2009; FERNANDES, 2012). Assim, a pressão antrópica produz inúmeros impactos ambientais extremamente significativos nas áreas costeiras, trazendo sérios problemas, muitas vezes superiores à capacidade do limiar de resiliência dos sistemas naturais e destruindo várias funções ambientais de diversas unidades de paisagem (COSTA; MELO; SOUZA, 2009).

Além da pressão antrópica, a zona costeira é bastante susceptível aos impactos das alterações climáticas, logo, os riscos nas zonas costeiras, muitas vezes, podem tornar-se catástrofes (ADGER et al., 2005). Para Kron (2008), as zonas litorâneas são as áreas com maior susceptibilidade à ocorrência de eventos naturais mais intensos, por exemplo. Processos erosivos em linhas de costas, mudanças ambientais globais e as formas de uso e ocupação do solo são algumas das variáveis de vulnerabilidade e riscos dos ambientes costeiros. Assim, a pressão antrópica produz inúmeros impactos ambientais extremamente significativos nas áreas costeiras, trazendo sérios problemas, muitas vezes superiores à capacidade do limiar de resiliência dos sistemas naturais e destruindo várias funções ambientais de diversas unidades de paisagem (COSTA; MELO; SOUZA, 2009).

Todas essas questões acabam por afetar um relevante papel econômico desempenhado pelas áreas litorâneas, que incluem o turismo e a pesca, que são a base da economia de muitas cidades litorâneas no mundo, principalmente no Brasil (SANTOS, 2012). Dessa forma, inúmeras famílias que dependem financeiramente de tais atividades são afetadas, o que pode contribuir para um cenário já instalado de exclusão social e econômica. 


\subsection{ASPECTOS LEGAIS DO GERENCIAMENTO COSTEIRO}

Como tentativa de equacionar tais problemas nas zonas costeiras, algumas políticas públicas voltadas à gestão dessas regiões necessitaram ser desenvolvidas. As políticas públicas podem ser entendidas como instrumentos desenvolvidos por órgãos governamentais e organizações não governamentais com o intuito de contribuir para a solução de problemas públicos (SILVA, 2016; KLEIN; GONÇALVES-DIAS, 2017). As políticas públicas são, portanto, compostas de atos jurídicos e normas desenvolvidos objetivando-se o "planejamento estratégico do Estado, num projeto de Estado e não apenas de governo ou de poder" (ARRETCHE, 2003; FREY, 2000; REIS, 2003; SOUZA, 2006, citados por CUNHA; SILVA e GOMES, 2017).

Organismos internacionais, tais como ONU (Organização das Nações Unidas), OEA (Organização dos Estados Americanos), COI (Comissão Oceanográfica Intergovernamental UNESCO), SCOR (Comitê Científico para Pesquisas Oceânicas), dentre outros, têm se engajado fortemente na gestão das áreas costeiras. Tal preocupação decorre do grande volume e extensão dos impactos das atividades antropogênicas e, portanto, da urgente necessidade de implementação de ações preventivas e de preservação dos recursos naturais desses ambientes (GRUBER, BARBOZA e NICOLODI, 2003).

Segundo Asmus et al. (2006), o gerenciamento costeiro integrado prevê ações em seis áreas prioritárias, a saber:

\footnotetext{
Planejamento (planejar usos e ocupação das áreas costeiras e oceânicas), proteção ambiental (proteção da base ecológica, preservação da biodiversidade e garantia do uso sustentável das áreas costeiras), promoção do desenvolvimento econômico (através do uso projetado em áreas costeiras, adjacentes e oceânicas), resolução de conflitos (equilíbrio e harmonização dos usos presentes e futuros), segurança pública (garantir a segurança frente a eventos naturais e antrópicos), e, gerenciamento de áreas públicas (garantir o correto uso de recursos comuns) (ASMUS et al., 2006, p. $02)$.
}

No Brasil, antes mesmo da promulgação da constituição, o Governo editou uma lei sobre a gestão do espaço litorâneo, a fim de assegurar a sustentabilidade do uso da zona costeira (GRANZIERA, 2009). Portanto, em 1988 foi instituído o Gerenciamento Costeiro através da Lei $\mathrm{n}^{\circ} 7.661$ que introduziu o Plano Nacional de Gerenciamento Costeiro (PNGC). Tal dispositivo legal veio com o intuito de "orientar a utilização racional dos recursos da zona costeira, de forma a contribuir para elevar a qualidade de vida de sua população, e a proteção de seu patrimônio natural, histórico, étnico e cultural". No ano anterior, em 1987 a Gestão Integrada da Zona Costeira já havia sido introduzida através da implementação do Programa Nacional de Gerenciamento Costeiro (GERCO), formulado pela Comissão Interministerial para os Recursos do Mar (CIRM) em 1987, com o objetivo de lançar as bases para as ações de planejamento e gestão integrada, descentralizada e participativa da zona costeira (SOUZA, 2009).

Em 1997 o PNGC passou por uma revisão e a Resolução CIRM (Comissão Interministerial para os Recursos do Mar) $\mathrm{n}^{\circ}$ 5, de 3 de dezembro de 1997, aprovou o PNGC II, em vigor até os dias atuais (MMA, 2013). Essa revisão foi necessária para trazer modificações no sentido de integrar todas as instâncias governamentais na estruturação e

DRd - Desenvolvimento Regional em debate (ISSNe 2237-9029) 
execução do Plano Nacional de Gerenciamento Costeiro, pois até então, a primeira versão do Plano restringia o campo de atuação da União e dos municípios e deixava grande parte das ações a cargos dos Estados (MMA, 2014). Ficou estabelecido, também no PNGC II a criação do Grupo de Integração do Gerenciamento Costeiro (GI-GERCO), coordenado pelo MMA e composto por representantes de 25 instituições, entre ministérios, autarquias, empresas públicas, Ministério Público, universidades, sociedade civil, estados e municípios.

A gestão das zonas costeiras no Brasil deve atender a alguns princípios como, por exemplo, garantir o cumprimento de acordos internacionais assumidos pelo país em relação ao uso dos recursos costeiros e direitos de liberdade à navegação; integrar a gestão dos ambientes terrestres e marinhos e compatibilizá-la com as políticas públicas em todas as esferas de atuação; consideração dos limites municipais para a operacionalização do processo de gestão; entre outros (AMADO, 2016).

O Decreto 5.300/2004 estabelece os diversos instrumentos que devem ser utilizados de forma integrada para a gestão da zona costeira no Brasil. O Plano Nacional de Gerenciamento Costeiro configura apenas um desses instrumentos, abordando as diretrizes mais gerais a serem aplicadas nas diferentes esferas de atuação. Outro instrumento é o PAF - Plano de Ação Federal da Zona Costeira - que deve conter o "planejamento de ações estratégicas para a integração de políticas públicas incidentes na zona costeira, buscando responsabilidades compartilhadas de atuação". Além destes, há também o Plano Estadual de Gerenciamento Costeiro (PEGC) que deve ser desenvolvido pelos Colegiados Costeiros, grupos de representação do Estado, Município e Sociedade Civil Organizada, cuja função é discutir planos, programas e ações para a Gestão Costeira, ressaltando o processo participativo na esfera estadual (GRANZIERA, 2009). As metas e diretrizes estabelecidas no Plano Estadual devem ser aplicadas em escala local pelos Planos Municipais de Gerenciamento Costeiro. Apesar disso, em muitos estados e municípios as ações dos Grupos de Integração do Gerenciamento Costeiro apresentam-se, ainda, embrionárias, o que coloca em xeque a qualidade ambiental destas áreas devido à persistência de atividades geradoras de grandes impactos (SCHERER et al., 2011 citado por ANDRADE; SCHERER, 2014).

Conforme o artigo 8 do Decreto $\mathrm{n}^{\mathrm{0}}$ 5.300/04, os Planos estaduais e Municipais de Gerenciamento Costeiro devem estabelecer: "I- os princípios, objetivos e diretrizes da política de gestão da zona costeira da sua área de atuação; II - o Sistema de Gestão Costeira na sua área de atuação; III - os instrumentos de gestão; IV - as infrações e penalidades previstas em lei; V - os mecanismos econômicos que garantam a sua aplicação".

Ainda segundo o Decreto ${ }^{0}$ 5.300/04 outros instrumentos que devem ser aplicados na gestão costeira são:

\footnotetext{
V- Sistema de Informações do Gerenciamento Costeiro - SIGERCO: componente do Sistema Nacional de Informações sobre Meio Ambiente - SINIMA, que integra informações georreferenciadas sobre a zona costeira;

VI - Sistema de Monitoramento Ambiental da Zona Costeira - SMA: estrutura operacional de coleta contínua de dados e informações, para o acompanhamento da dinâmica de uso e ocupação da zona costeira e avaliação das metas de qualidade socioambiental;

VII - Relatório de Qualidade Ambiental da Zona Costeira - RQA-ZC: consolida, periodicamente, os resultados produzidos pelo monitoramento ambiental e avalia a eficiência e eficácia das ações da gestão;
}

DRd - Desenvolvimento Regional em debate (ISSNe 2237-9029) 
VIII - Zoneamento Ecológico-Econômico Costeiro - ZEEC: orienta o processo de ordenamento territorial, necessário para a obtenção das condições de sustentabilidade do desenvolvimento da zona costeira, em consonância com as diretrizes do Zoneamento Ecológico-Econômico do território nacional, como mecanismo de apoio às ações de monitoramento, licenciamento, fiscalização e gestão;

IX - macrodiagnóstico da zona costeira: reúne informações, em escala nacional, sobre as características físico-naturais e socioeconômicas da zona costeira, com a finalidade de orientar ações de preservação, conservação, regulamentação e fiscalização dos patrimônios naturais e culturais.

De acordo com o MMA (BRASIL, 2008), além dos planos e políticas diretamente ligadas à esta temática existem outros instrumentos que devem ser desenvolvidos em consonância para a gestão das áreas costeiras, como a Política de Recursos Hídricos, Resíduos Sólidos, Saneamento, a legislação sobre Patrimônio da União e o Estatuto da Cidades, além das ações relacionadas a áreas protegidas, pesca, exploração de recursos naturais, turismo, navegação e defesa nacional, entre outras. Neste sentido, de acordo com Granziera (2009), existe uma falha na gestão integrada brasileira, pois as políticas de gerenciamento costeiro e de recursos hídricos são gerenciadas por instituições distintas, não sendo considerada a zona costeira como parte integrante da bacia hidrográfica.

Ainda na zona costeira, a orla marítima merece especial atenção. Mais uma vez conforme o Decreto 5.300/04, a gestão da orla marítima tem o objetivo de implementar ações com a finalidade de disciplinamento no uso e ocupação do solo dessas áreas, compatibilizando-as, especialmente, com o Zoneamento Ecológico Econômico (ZEE). Introduz-se, neste contexto, o Projeto de Gestão Integrada da Orla Marítima (Projeto Orla). Os municípios que desejarem aderir ao projeto (o Projeto Orla é um ato voluntário) deve assumir o compromisso em desenvolver todas as fases de implantação (BULHOES et al., 2016).

Outro aspecto importante a se observar nas áreas costeiras são as regras específicas, estabelecidas pela Lei $\mathrm{n}^{\mathrm{o}} 7.661 / 88$, para o licenciamento ambiental de atividades. Portanto, o licenciamento ambiental para parcelamento do solo, construção, instalação, funcionamento e ampliação de atividades está condicionada à apresentação de Estudo de Impacto Ambiental e o respectivo Relatório de Impacto Ambiental - EIA/RIMA. Para Granziera (2009), atividades que provoquem "a degradação dos ecossistemas, do patrimônio e dos recursos naturais da Zona Costeira, gerará, para seu autor, a obrigação de reparar o dano causado”.

Bernardes e Leone Oliveira (2015) ressaltam a dificuldade para a determinação da competência para o licenciamento na zona costeira, tendo em vista que a região apresenta aspectos físicos e econômicos interligados. A Lei Complementar $n^{\circ} 140 / 2011$, em seu artigo $7^{\circ}$, parágrafo único, estabelece que:

O licenciamento dos empreendimentos cuja localização compreenda concomitantemente áreas das faixas terrestre e marítima da zona costeira será de atribuição da União exclusivamente nos casos previstos em tipologia estabelecida por ato do Poder Executivo, a partir de proposição da Comissão Tripartite Nacional, assegurada a participação de um membro do Conselho Nacional do Meio Ambiente (Conama) e considerados os critérios de porte, potencial poluidor e natureza da atividade ou empreendimento.

DRd - Desenvolvimento Regional em debate (ISSNe 2237-9029) 
Portanto, nos casos não previstos por tal ato do Poder Executivo, o licenciamento poderá ficar a cargo do Estado ou município, dependendo da situação. Porém não restam dúvidas quanto à atuação supletiva dos órgãos licenciadores. Sendo assim, caso o município, originalmente responsável pelo licenciamento de uma dada atividade, não possuir capacidade técnica, a responsabilidade pelo licenciamento ficará a cargo do Estado. Supletivamente, caso o Estado não possua capacidade técnica para o licenciamento este será de responsabilidade da União. Entretanto, assim como estabelecido pelo artigo 13 da Lei Complementar $\mathrm{n}^{{ }^{\circ}}$ 140/2011, o licenciamento será realizado por um único ente federativo. Não obstante, os demais entes federativos podem manifestar interesse ao órgão responsável, desde que os prazos e procedimentos do licenciamento ambiental sejam obedecidos. Já no tocante à fiscalização, está é uma competência comum, em que todos os entes federativos têm o direito e o dever de fiscalizar as atividades e empreendimentos potencialmente degradadores (BERNARDES; LEONE OLIVEIRA, 2015).

Tudo isso demonstra a complexidade que envolve a gestão costeira, devido a interação entre setores distintos, com a necessidade de articulação institucional, entre Estados e Municípios objetivando assegurar o equilíbrio ecológico (GRANZIERA, 2009).

\section{RESULTADOS E DISCUSSÃO}

A análise de conteúdo do Plano Nacional de Gerenciamento Costeiro (PNGC) e o seu respectivo relatório " 25 anos do Gerenciamento costeiro no Brasil" permitiu inferir que neste ínterim diversas são as ações desenvolvidas no intuito de regular as atividades nessas áreas com o intuito de manter as características intrínsecas dessa região tão importante do ponto de vista econômico, social e ambiental. A partir dessa análise, foi possível identificar as principais atividades econômicas desenvolvidas na zona costeira brasileira (Quadro 01), bem como os principais problemas ocorridos nessas áreas (Quadro 02).

Quadro 01 - Atividades econômicas desenvolvidas na área costeira

\begin{tabular}{|c|c|c|}
\hline Unidades de Contexto & Subunidades de Contexto & \\
\hline \multirow{4}{*}{ Atividades } & & Petróleo e gás \\
\cline { 3 - 3 } & \multirow{3}{*}{$\begin{array}{c}\text { Atividades econômicas } \\
\text { desenvolvidas na área costeira }\end{array}$} & Setor elétrico \\
\cline { 3 - 3 } & & Turismo \\
\cline { 3 - 3 } & & Pesca \\
\cline { 3 - 3 } & & Carcinicultura \\
\cline { 3 - 3 } & & Portos \\
\hline
\end{tabular}

Fonte: Elaborado pelo autor

De acordo com Souza (2009), a zona costeira brasileira sofre inúmeras pressões ocasionadas, entre outros, pelo processo de urbanização acelerado e desordenado, o que culmina em intensa degradação ambiental e da qualidade de vida das populações. São 
diversas as atividades desenvolvidas nas áreas costeiras, assim como mostra o Quadro 01 acima, que geram impactos neste ecossistema.

Diversos impactos, como os mostrados no Quadro 02 abaixo acabam por afetar um relevante papel econômico desempenhado pelas áreas litorâneas, que incluem o turismo e a pesca, que são a base da economia de muitas cidades litorâneas no mundo, principalmente no Brasil (SANTOS, 2012). Dessa forma, inúmeras famílias que dependem financeiramente de tais atividades são afetadas, o que pode contribuir para um cenário já instalado de exclusão social e econômica.

Quadro 02 - Principais impactos ocorridos nas áreas costeiras brasileiras

\begin{tabular}{|c|c|c|}
\hline Unidades de Contexto & Subunidades de Contexto & \\
\hline \multirow{11}{*}{ Problemas } & \multirow{11}{*}{$\begin{array}{c}\text { Principais Impactos nas áreas } \\
\text { costeiras }\end{array}$} & Derramamento de óleo \\
\hline & & $\begin{array}{c}\text { Urbanização (impermeabilização da costa; } \\
\text { ocupações irregulares) }\end{array}$ \\
\hline & & Erosão \\
\hline & & Supressão da vegetação de mangue e restinga \\
\hline & & Conflitos de usos do solo \\
\hline & & Contaminação hídrica \\
\hline & & Impactos sobre a pesca \\
\hline & & Dragagem \\
\hline & & Aumento de ruídos \\
\hline & & Emissão de poluentes atmosféricos \\
\hline & & Geração de resíduos sólidos \\
\hline
\end{tabular}

Fonte: Elaborado pelo autor

No caso da erosão costeira, esta pode ser agravada, em especial, por obras de engenharia, dentre elas, estabilização de canais de maré, canais de acesso e estruturas de abrigo a portos ou terminais marítimos, construção de espigões. Tais obras podem desequilibrar o balanço sedimentar e, durante muitos anos, o equilíbrio morfológico da área costeira não era levado em consideração (NEVES; MUEHE, 2008).

Outra problemática presente nas zonas costeiras são as inundações. Estas afetam de maneira mais incisiva, as planícies costeiras de sistemas lagunares. As características inerentes a estes ambientes associados aos problemas de macrodrenagem pertencentes ao cenário de inúmeras cidades brasileiras geram inúmeros prejuízos, sejam do ponto de vista econômico quanto social (SANTOS, 2012).

Dada a frequência de acidentes envolvendo derramamentos de óleo, algumas ações têm sido desenvolvidas, por indústrias e governos no sentido de reduzir os riscos dessas ações. A ANP (Agência Nacional do Petróleo) juntamente com o MMA (Ministério do Meio Ambiente) desenvolveram em 2004 as Especificações e Normas Técnicas para Elaboração de Cartas de Sensibilidade ao Derramamento de Óleo (Cartas SAO) para o litoral brasileiro. Estes documentos trazem informações sobre os recursos biológicos e socioeconômicos sensíveis ao óleo (NOERNBERG et al., 2008). Em decorrência disso, muitos estudos têm sido feitos objetivando a elaboração de mapas de sensibilidade ao derramamento de óleo (BELLOTTO; SAROLLI, 2008; PERINOTTO, 2010; BOULHOSA; SOUZA FILHO, 2008). 
Tais mapas são essenciais para a elaboração do plano de contingência aos derrames de petróleo, facilitando o processo de tomada de decisões (NOERNBERG et al., 2008).

Preocupantemente, têm-se, ainda, os impactos sobre os mangues e restingas, considerados como um dos ambientes costeiros mais produtivos. Conforme Krug; Leão; Amaral (2007), o manguezal brasileiro é um dos maiores do mundo e são de fundamental importância para a manutenção da qualidade da água, fixação do sedimento, fornecimento de produção primária para o entorno e manutenção da biodiversidade. Sinais da incipiente gestão das atividades desenvolvidas nas áreas costeiras são as pressões sofridas pelos manguezais em todo o território brasileiro que, relacionam-se com o aumento da população nessas regiões, intensificação de atividades industriais e portuárias, além da superexploração de seus recursos naturais (KRUG; LEÃO; AMARAL, 2007).

Dentre essas pressões, Oliveira; Mattos (2007, p.184), destacam ainda, a carcinicultura, atividade com acentuado crescimento nas últimas quatro décadas, influenciada pela demanda dos mercados norte-americano, japonês e europeu. Segundo os autores, a "construção indiscriminada de tanques de carcinicultura e canais de abastecimento de água representa redução nas áreas de manguezais que podem afetar o ecossistema regional".

Foi possível, ainda, identificar os principais instrumentos utilizados para a gestão das áreas costeiras no Brasil. Esses instrumentos dividem-se entre Planos, Programas, Projetos e Legislações, conforme o Quadro 03 a seguir:

Quadro 03- Instrumentos para a Gestão Costeira no Brasil

\begin{tabular}{|c|c|c|}
\hline Unidades de Contexto & Subunidades de Contexto & \\
\hline \multirow{15}{*}{ Instrumentos de gestão } & \multirow{6}{*}{ Planos } & Planos de Área (Decreto n ${ }^{\circ} 4871 / 2003$ ) \\
\hline & & $\begin{array}{c}\text { Plano Nacional de Contingência para Incidentes de } \\
\text { Poluição por Óleo em Águas sob Jurisdição } \\
\text { Nacional-PNC (Decreto n }{ }^{\circ} 8.127 \text {, de } 22 \text { de outubro } \\
\text { de } 2013\end{array}$ \\
\hline & & $\begin{array}{c}\text { Plano Nacional de Logística de Transportes } \\
\text { (Atividade Portuária) }\end{array}$ \\
\hline & & $\begin{array}{c}\text { Plano Nacional de Logística Portuária (Atividade } \\
\text { Portuária) }\end{array}$ \\
\hline & & $\begin{array}{l}\text { Plano Nacional de Logística Integrada (Atividade } \\
\text { Portuária) }\end{array}$ \\
\hline & & Planos de Recursos Hídricos \\
\hline & \multirow{4}{*}{ Programas } & $\begin{array}{l}\text { Sistema de Informações do Gerenciamento Costeiro } \\
\text { - SIGERCO }\end{array}$ \\
\hline & & $\begin{array}{l}\text { Relatório de Qualidade Ambiental da Zona Costeira } \\
\text { - RQA-ZC }\end{array}$ \\
\hline & & $\begin{array}{c}\text { Sistema de Monitoramento Ambiental da Zona } \\
\text { Costeira - SMA-ZC }\end{array}$ \\
\hline & & $\begin{array}{c}\text { Programa } 2040 \text { (Gestão de Riscos e Respostas a } \\
\text { Desastres) }\end{array}$ \\
\hline & \multirow{3}{*}{ Projetos } & Operação Verão (Marinha) \\
\hline & & Agenda Ambiental Portuária (Atividade Portuária) \\
\hline & & Projeto "Nado Livre" (Marinha) \\
\hline & \multirow[t]{2}{*}{ Legislações } & $\begin{array}{c}\text { Lei } n^{\circ} 7.661 \text { (Plano Nacional } \\
\text { de Gerenciamento Costeiro- PNGC). }\end{array}$ \\
\hline & & Decreto no 74.557 , de 12 de setembro de 1974 \\
\hline
\end{tabular}

DRd - Desenvolvimento Regional em debate (ISSNe 2237-9029) 


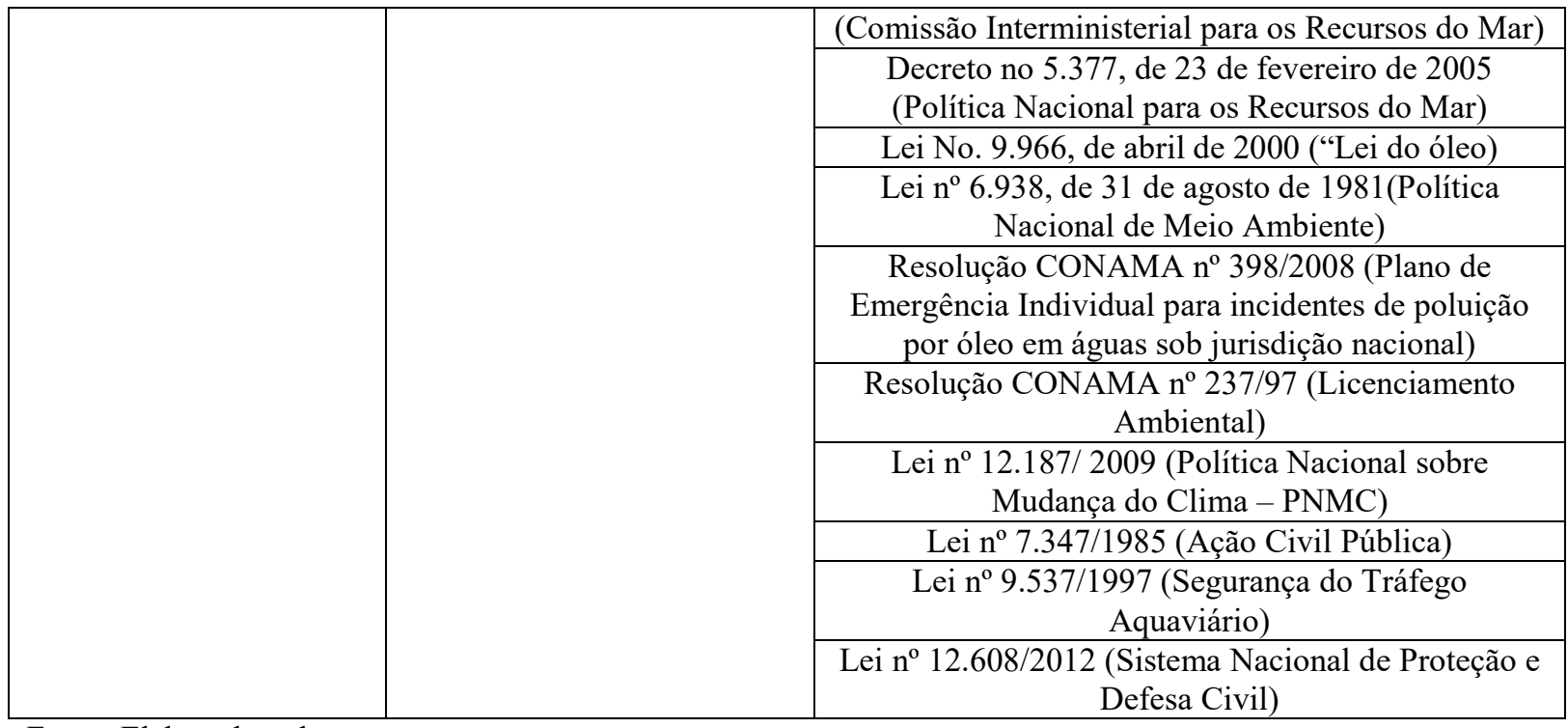

Fonte: Elaborado pelo autor

Gestão Costeira Integrada no Brasil é impulsionada a partir da intensificação dos impactos ocasionados pela industrialização e urbanização (MARTINEZ, 2012). O modelo de administração da Gestão Costeira Integrada adotada no Brasil bem como em outros países, seguem propostas internacionais (Integrated Coastal Area Manegement - ICAM, Joint Group of Experts on the Scientific Aspects of Marine Environment Protection - GESAMP) (HENOCQUE E DENNIS, 2001; GESAMP, 1996). Segundo Martinez (2012), todas elas guardam estreita relação com o modelo administrativo PDCA (Plan, Do, Check, Act), bastante utilizado na gestão de ambientes empresariais.

A criação de instrumentos, especialmente os legais, para auxiliar a gestão das áreas costeiras é alavancada pelo destaque dado à Zona Costeira pela Constituição Federal de 1988 definindo-a como patrimônio nacional (MARTINEZ, 2012). Esse destaque é reafirmado pela aprovação do Plano Nacional de Gerenciamento Costeiro, Lei $\mathrm{n}^{\circ} 7.661 / 88$, o que trouxe articulação entre a Política Nacional para os Recursos do Mar, instituída pelo Decreto de 1980, a Política Nacional de Meio Ambiente, Lei 6.938/1981 e demais legislações ambientais.

Outros instrumentos, os planos, em especial os de emergência na área marítimocosteira ganharam notoriedade a partir da ocorrência de acidentes envolvendo, especialmente, navios petroleiros em terminais marítimos, em instalações de refino e em plataformas de exploração e produção de petróleo e gás (BARROS; WASSERMAN; LIMA, 2010). Esses planos devem ser aplicados e desenvolvidos em consonância com as legislações aplicáveis à temática com o objetivo de prevenir e minimizar os danos decorrentes de acidentes, como os já citados. Entretanto, os autores supracitados destacam que uma imprescindível articulação entre os planos, órgãos ambientais e órgãos de defesa civil é necessária, em nível local e regional, ainda é incipiente devido à dificuldade de se estabelecer uma coordenação integrada das ações. Além disso, segundo ANTAQ (2007) apud Barros; Wasserman e Lima (2010), grande parte dos portos brasileiros não conseguiu cumprir todas suas determinações legais, principalmente a que estabelece a criação de planos de ajuda mútua entre os seus diversos terminais. Isso demonstra a desarticulação entre os diversos instrumentos existentes, enfraquecendo à gestão integrada das zonas costeiras no Brasil. 
Dentre as principais instituições atuantes na gestão costeira no Brasil encontram-se: Ministérios, Secretarias, Autarquia, Agências reguladoras, Associações e Empresa (Quadro 04).

Quadro 04 - Instituições atuantes na gestão costeira no Brasil

\begin{tabular}{|c|c|c|}
\hline $\begin{array}{l}\text { Unidades de } \\
\text { Contexto }\end{array}$ & $\begin{array}{l}\text { Subunidades de } \\
\text { Contexto }\end{array}$ & \\
\hline \multirow{21}{*}{ Instituições } & \multirow{12}{*}{ Ministérios } & Ministério do Meio Ambiente \\
\hline & & Ministério das Relações Exteriores \\
\hline & & Ministério dos Transportes \\
\hline & & Ministério do Desenvolvimento, Indústria e Comércio Exterior \\
\hline & & Ministério de Minas e Energia \\
\hline & & Ministério do Planejamento, Orçamento e Gestão \\
\hline & & Ministério da Ciência, Tecnologia e Inovação \\
\hline & & Ministério do Turismo \\
\hline & & Ministério da Integração Nacional \\
\hline & & Ministério das Cidades \\
\hline & & Ministério da Pesca e Aquicultura \\
\hline & & Ministério Público Federal \\
\hline & \multirow[t]{2}{*}{ Secretarias } & $\begin{array}{c}\text { Secretaria da Comissão Interministerial para os Recursos do } \\
\text { Mar }\end{array}$ \\
\hline & & Secretaria do Patrimônio da União \\
\hline & \multirow[t]{2}{*}{ Autarquia } & $\begin{array}{c}\text { Instituto Brasileiro de Meio Ambiente e dos Recursos Naturais } \\
\text { Renováveis } \\
\text { (IBAMA) }\end{array}$ \\
\hline & & $\begin{array}{l}\text { Instituto Chico Mendes de Conservação da Biodiversidade } \\
\text { (ICMBio) }\end{array}$ \\
\hline & \multirow{2}{*}{ Agências reguladoras } & Agência Nacional de Transportes Aquaviários (ANTAQ) \\
\hline & & Agência Nacional de Águas (ANA) \\
\hline & \multirow{2}{*}{ Associações } & $\begin{array}{c}\text { Associação Brasileira de Entidades Estaduais de Meio } \\
\text { Ambiente (ABEMA) }\end{array}$ \\
\hline & & $\begin{array}{l}\text { Associação Nacional de Órgãos Municipais de Meio Ambiente } \\
\text { (ANAMMA) }\end{array}$ \\
\hline & Empresa & Petrobras \\
\hline
\end{tabular}

Fonte: Elaborado pelo autor

De acordo com Scherer, Sancheze Negreiros (2010, p. 297), a “[...] multiplicidade de instituições, processos, normas e controles de diferentes naturezas, associadas à organização político-administrativas territorial do Brasil trazem dificuldades ao gerenciamento costeiro no país". Como é possível observar no Quadro 04 acima, de fato são inúmeras instituições ligadas, direta ou indiretamente à Gestão Costeira Integrada no Brasil nos últimos 25 anos, que vão desde empresas e associações até Ministérios. Muitas áreas costeiras sofrem, ainda com a ausência do poder público, o que segundo Szlafsztein (2009, p. 54), “[...] dificulta a materialização de políticas e estratégias, deixando para os ocupantes privados (legais ou não) o poder de tomar decisões, realizadas de forma empírica e através de uma visão parcial, que frequentemente prioriza o próprio benefício".

A Constituição Federal de 1988 estabelece as competências administrativas, sejam da União, Estados e Municípios. Dessa forma, o Plano Nacional de Gerenciamento Costeiro 
aponta para mecanismos de articulação entre as três esferas públicas na atuação da gestão costeira no Brasil, sendo a coordenação dessa Gestão no âmbito Federal do Ministério do Meio Ambiente - MMA. O COGERCO (Grupo de Coordenação da Gestão Costeira) juntamente com o CIGERCO (Grupo de Integração do Gerenciamento Costeiro são responsáveis pela "articulação política e definição das diretrizes de atuação do programa" (PLANO NACIONAL DE GERENCIAMENTO COSTEIRO II apud SCHERER; SANCHEZ; NEGREIROS, 2010. p. 315).

$\mathrm{Na}$ esfera estadual a coordenação do gerenciamento costeiro fica a cargo de diversas instituições, desde às organizações estaduais de meio ambiente até órgãos de planejamento urbano e territorial. O mesmo acontece a nível municipal em uma escala bastante incipiente (SCHERER; SANCHEZ; NEGREIROS, 2010).

Conforme Clark (1996 apud GRUBER; BARBOZA; NICOLODI 2003), muitos governos desenvolvem programas para áreas costeiras que são operados por várias agências, as quais não apresentam sintonia entre si. Isso acaba gerando uma falta de coordenação entre todos os envolvidos e as ações desenvolvidas são insuficientes para a gestão das áreas costeiras.

Nos 25 anos da gestão costeira integrada no Brasil foi possível identificar algumas carências dessa região, conforme mostra o Quadro 05 abaixo:

Quadro 05 - Principais carências da região costeira brasileira

\begin{tabular}{|c|c|c|}
\hline $\begin{array}{c}\text { Unidades de } \\
\text { Contexto } \\
\end{array}$ & Subunidades de Contexto & \\
\hline \multirow{15}{*}{ Carências } & \multirow{15}{*}{$\begin{array}{c}\text { Principais necessidades de } \\
\text { desenvolvimento e/ou } \\
\text { aperfeiçoamento para o } \\
\text { Gerenciamento Costeiro }\end{array}$} & Estudos Geológicos \\
\hline & & Arranjos logísticos \\
\hline & & Desenvolvimento Científico e Tecnológico \\
\hline & & Sistema de Monitoramento da Costa Brasileira \\
\hline & & Gestão dos espaços \\
\hline & & Capacitação profissional \\
\hline & & Fortalecimento institucional \\
\hline & & Plano Diretor \\
\hline & & Zoneamento Ecológico-Econômico \\
\hline & & Zoneamento Costeiro Municipal \\
\hline & & Gestão Integrada da Orla Marítima \\
\hline & & Plano de Desenvolvimento da Aquicultura \\
\hline & & $\begin{array}{c}\text { Plano Nacional de Desenvolvimento da } \\
\text { Carcinicultura } \\
\end{array}$ \\
\hline & & $\begin{array}{c}\text { Sistema de Gestão Compartilhada do Uso } \\
\text { Sustentável dos Recursos Pesqueiros }\end{array}$ \\
\hline & & Plano Safra da Pesca e Aquicultura \\
\hline
\end{tabular}

Fonte: Elaborado pelo autor

No entanto, as ações de operacionalização do programa nos municípios da zona costeira são ainda bastante incipientes. Essa falta de uma execução de fato das ações propostas para uma melhor gestão ambiental da costa, tem facilitado a perpetuação de atividades não sustentáveis e a perda gradativa de recursos e serviços ambientais. 
Ainda que a Gestão Costeira Integrada no Brasil já tenha mais de 25 anos de existência, suas ações de operacionalização são bastante incipientes e a região costeira apresenta inúmeras carências e necessidades de melhoria no Brasil, a exemplo do Quadro 05 acima. O crescimento urbano, de maneira geral, não apenas nas áreas costeiras, ocorre de maneira desordenada, sem o acompanhamento fiscalizatório e de controle legais, tão necessários para a contenção do avanço das ações degradadoras do meio ambiente (VASCONCELOS; CORIALANO, 2008). E neste sentido, os autores ainda completam que o poder público não responde ao crescimento urbano adequadamente e em tempo de evitar o comprometimento socioambiental das cidades.

A própria multiplicidade de agentes responsáveis pela Gestão Costeira no país, apresentada no Quadro 04, contribui para a geração das diversas carências dessa região, tendo em vista a falta de coordenação entre todos esses responsáveis, o que acaba por gerar ações insatisfatórias de gestão integrada.

Segundo Andrade e Scherer (2014), o Plano Nacional de gerenciamento Costeiro prevê a necessidade de aplicação dos instrumentos de gestão nas esferas estaduais e municipais. Entretanto, segundo as autoras há uma grande dificuldade neste sentido, pois apenas pouco mais da metade dos estados costeiros apresentam algum instrumento de gerenciamento costeiro. "Nenhum estado costeiro possui o Zoneamento Ecológico Econômico Costeiro (ZEEC) e o Plano de Gestão da Zona Costeira (PGZC) completamente implantados, sendo que nenhum possui mecanismos de avaliação das ações gerenciais e da sua estrutura para a gestão costeira" (ANDRADE, 2013 apud ANDRADE; SCHERER, 2014. p. 141).

Para que as carências da zona costeira brasileira sejam sanadas do ponto de vista da Gestão Costeira Integrada é necessário, entre outros, “[...] a revisão dos Planos de Gestão da Orla, uma melhor definição das formas de apoio e implementação das ações propostas nos Planos de Gestão, a melhoria da efetividade da atuação das Comissões Técnicas Estaduais e o acompanhamento dos Comitês Gestores Locais" (OLIVEIRA; NICOLODI, 2012. p.99). Ainda segundo os autores é necessário priorizar um processo de mobilização local mais efetivos, com um maior envolvimento das comunidades e processos participativos.

\section{CONSIDERAÇÕES FINAIS}

Com esta pesquisa foi possível avaliar a evolução que a gestão costeira brasileira tem enfrentado desde a sua institucionalização. De maneira geral, a área costeira brasileira apresenta grande biodiversidade e múltiplos usos, o que contribui para o surgimento de inúmeros conflitos de interesses e, consequentemente, impactos sociais, econômicos, culturais e, sobretudo, ambientais. O desafio, portanto, configura-se em compatibilizar as atividades realizadas na zona costeira - que contribuem sobremaneira para o desenvolvimento econômico do país - com a sustentabilidade ecológica dos ecossistemas litorâneos. Foi neste sentido que a gestão costeira desenvolveu ações de políticas públicas objetivando manter a qualidade ambiental e a produtividade das áreas costeiras, bem como o ordenamento do uso e ocupação do solo litorâneo. 
Os instrumentos legais, planos, programas e projetos desenvolvidos têm trazido resultados positivos em direção ao gerenciamento dos usos das zonas litorâneas, com vistas à mitigação de inúmeros impactos, evitando prejuízos de diversas ordens. Entretanto, torna-se imprescindível uma melhor articulação entre todos os órgãos e instituições envolvidas com a gestão costeira brasileira para que melhores resultados sejam alcançados. Apesar das iniciativas já citadas e o envolvimento de diversos órgãos e instituições há ainda carências na gestão costeira que deverão ser sanadas para a promoção do ordenamento do uso dos recursos naturais e da ocupação dos espaços costeiros.

Portanto, para a continuidade da gestão costeira no Brasil em seus próximos anos é imprescindível que o planejamento de ações leve em consideração os pontos positivos e negativos destes primeiros 25 anos do gerenciamento costeiro.

\section{REFERÊNCIAS}

ADGER, W. N. et al. Social-Ecological Resilience to Coastal Disasters. Science, v. 309, p. 1036-1039, Aug. 2005.

AMADO, F. A. T. Direito ambiental esquematizado. 7.ed. rev. e atual. Rio de Janeiro: Forense; São Paulo: Método, 2016.

ANDRADE, J. Gerenciamento Costeiro no Brasil: ZEEC e Plano Diretor (Estudo de caso Paulista/PE). 2013. 144 f. Dissertação (Mestrado) - Curso de Pós-graduação em Planejamento Territorial e Desenvolvimento Socioambiental, Centro de Ciências Humanas e da Educação, Universidade do Estado de Santa Catarina, Florianópolis, 2013.

ANDRADE, J.; SCHERER, M. E. G. Decálogo da gestão costeira para Santa Catarina: avaliando a estrutura estadual para o desenvolvimento do Programa Estadual de Gerenciamento Costeiro. Desenvolvimento e Meio Ambiente, v. 29, p. 139-154, abr. 2014.

ANTAQ. Relatório Consolidado das Avaliações em 2006 e 2007 da Gestão Ambiental nos Portos Organizados. Brasília: Gerência de Meio Ambiente, 2007a.

ARRETCHE, M. Dossiê agenda de pesquisas em políticas públicas. Revista Brasileira de Ciências Sociais, v. 18, n. 51, p. 7-10, 2003.

ASMUS, M.L. et al. Gestão costeira no Brasil: instrumentos, fragilidades e potencialidades. Revista de Gestão Costeira Integrada, a. 4, n. 5, p. 52-57, 2006.

BARDIN, L. Análise do conteúdo. Lisboa: Edições 70, 2011.

BARROS, S. R. S.; WASSERMAN, J. C.; LIMA, G. B. A. Risco Ambiental na zona costeira: uma proposta interdisciplinar de gestão participativa para os Planos de Controle a Emergências dos portos brasileiros. Revista da Gestão Costeira Integrada, v. 10, n. 2, p. 217-227, 2010. 
BELLOTTO, V. R.; SAROLLI, V. M. M. Mapeamento da sensibilidade ambiental ao derramamento de óleo e ações de resposta para a região costeira e área portuária de Imbituba, SC, Brasil. Braz. J. Aquat. Sci. Technol., v. 12, n. 2, p. 115-125, 2008.

BERNARDES, L.; LEONE-OLIVEIRA, M. Competência para o licenciamento ambiental e questões pontuais sobre o poder de polícia ambiental na zona costeira. Revista Jus Navigandi, Teresina, a. 20, n. 4515, 11 nov. 2015.

BRASIL. Constituição da República Federativa do Brasil. Brasília, DF: Senado Federal: Centro Gráfico, 1988.

Decreto $\mathbf{n}^{0} 5.300$ de 7 de dezembro de 2004. Regulamenta a Lei $n^{\circ} 7.661$, de 16 de maio de 1988, que institui o Plano Nacional de Gerenciamento Costeiro - PNGC, dispõe sobre regras de uso e ocupação da zona costeira e estabelece critérios de gestão da orla marítima, e dá outras providências. Brasília: D.O.U. de 8.12.2004.

Lei $\mathbf{n}^{0}$ 7.661, de 16 de maio de 1988. Institui o Plano Nacional de Gerenciamento

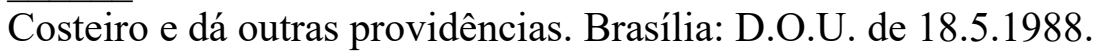

. Ministério do Meio Ambiente (MMA). Projeto Orla. Brasília, 2008.

Relatório de gestão: gerência costeira 2010-1012. Brasília, 2013.

Os 25 anos do gerenciamento costeiro no Brasil: Plano Nacional de

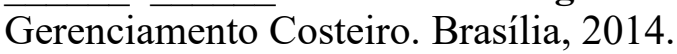

BOULHOSA, M. B. M.; SOUZA FILHO, P. W. M. Reconhecimento e mapeamento dos ambientes costeiros para geração de mapas de ISA ao derramamento de óleo, Amazônia Oriental. Revista Brasileira de Geofísica, n. 27 (Supl. 1), p. 23-37, 2009.

BULHOES, E. M. R. et al. Projeto de gestão integrada da orla marítima. A experiência do município de Campos dos Goytacazes, Rio de Janeiro, Brasil. Soc. nat., Uberlândia, v. 28, n. 2, p. 285-300, Aug. 2016.

CLARK, J. Integrated Coastal Zone Management - A world wide challenge to comprehend Shoreline and Coastal Waters as single unit. Sea Tecnhonology, Arlington, Virginia. USA, v. 37, n. 6. 1996.

COSTA, J. J.; MELO E SOUZA, R. Biorecuperação de dunas costeiras do município de Pirambu/SE. In: SOUZA, R. M. (Org.). Território, planejamento e sustentabilidade: conceitos e práticas. São Cristóvão: Editora, UFS, 2009.

CUNHA, B. P., SILVA, J. I. A. O., GOMES, I. R. F. D. Políticas Públicas Ambientais: judicialização e ativismo judiciário. Rev. Fac. Der., Montevideo, n. 42, p. 153-179, 2017.

FERNANDES, D. F. O zoneamento ecológico-econômico costeiro e considerações acerca do zoneamento ecológico-econômico do estado de São Paulo. In: GRANZIERA, M. L. M.; GONÇALVES, A. (Orgs.). Os problemas da zona costeira no Brasil e no mundo. Santos: Editora Universitária Leopoldianum, 2012. 
FREY, K. Políticas Públicas: um debate conceitual e reflexões referentes à prática da análise de políticas públicas no Brasil. Planejamento e Políticas Públicas, v. 21, n. 1, p. 212-259, 2000 .

GRANZIERA, M. L. M. Direito ambiental. São Paulo: Atlas, 2009.

GRUBER, N. L. S.; BARBOZA, E. G.; NICOLODI, J. L. Geografia dos sistemas costeiros e oceanográficos: subsídios para gestão integrada da zona costeira. Gravel, Porto Alegre, n. 1, p. 81-89, jan. 2003.

KLEIN, F. B., GONÇALVES DIAS, S. L. F. A deposição irregular de resíduos da construção civil no município de São Paulo: um estudo a partir dos instrumentos de políticas públicas ambientais. Desenvolvimento e Meio Ambiente, v. 40, p. 483-506, 2017.

KRON, W. Coasts: The riskiest places on Earth. In: International Conference on Coastal Engineering (ICCE), Hamburg, Germany, 2008.

KRUG, L. A.; LEÃO, C.; AMARAL, S. Dinâmica espaço-temporal de manguezais no Complexo Estuarino de Paranaguá e relação entre decréscimo de áreas de manguezal e dados sócio-econômicos da região urbana do município de Paranaguá - Paraná. XIII Simpósio Brasileiro de Sensoriamento Remoto, v. 13. Florianópolis- SC.

MARTINEZ, D. I. Representações e percepções sobre ambiente e conservação como subsídio ao Gerenciamento Costeiro Integrado: estudo de caso com grupos sociais da região de Cananéia, litoral sul do Estado de São Paulo. Dissertação (Mestrado) Universidade de São Paulo, Instituto Oceanográfico, 2012.

MORAES, R. Uma tempestade de luz: a compreensão possibilitada pela análise textual discursiva. Ciência \& Educação. v. 9, n. 2, p. 191-211, 2003.

NEVES, C. F.; MUEHE, D. Vulnerabilidade, impactos e adaptação a mudanças do clima: a zona costeira. Parcerias Estratégicas, Brasília, DF, n. 27, p. 217-295, dez. 2008.

NOERNBERG, M. A. et al. Determinação da sensibilidade do litoral paranaense à contaminação por óleo. Braz. J. Aquat. Sci. Technol., v. 12, n. 2, p. 49-59, 2008.

OLIVEIRA, A. C. de A. Ecodinâmica das dunas costeiras de Sergipe. Dissertação (Mestrado em Geografia). Núcleo de Pós-Graduação em Geografia. Pró-reitoria de pósgraduação e pesquisa. Universidade Federal de Sergipe, São Cristóvão, 2008.

OLIVEIRA, G. D.; MATOS, K. M. C. Impactos ambientais provocados pela indústria de camarão no município de Nísia Floresta (RN). Revista Ibero Americana de Estratégia, São Paulo, v. 6, n. 2, p. 183-188, 2007.

OLIVEIRA, M. R. L.; NICOLODI, J. L. A Gestão Costeira no Brasil e os dez anos do Projeto Orla. Uma análise sob a ótica do poder público. Revista da Gestão Costeira Integrada, v. 12, n. 1, p. 89-98, 2012. 
PERINOTTO, R. R. C. Mapeamento de sensibilidade ao derrame de óleo dos ambientes costeiros dos municípios de São Vicente, Santos e Guarujá - SP. 2010. Dissertação (Mestrado) - Curso de Pós-graduação em Geociências e Meio Ambiente, Instituto de Geociências e Ciências Exatas, Universidade Estadual Paulista, Rio Claro, 2010.

SANTOS, R. T. F. Mudanças climáticas e a zona costeira: uma análise do impacto da subida do nível do mar nos recursos hídricos - o caso do Canal de São Francisco - Baía de Sepetiba - RJ. 2012. Dissertação (Mestrado) - UFRJ/ COPPE/ Programa de Planejamento Energético, 2012.

SCHERER, M., et al. El manejo costero en Brasil: análisis de la situación y propuestas para una posible mejora. In: FARINÓS DASÍ, J. (Ed. y Coord.). La Gestión Integrada de Zonas Costeras ¿Algo más que una Ordenación del Litoral Revisada? La GIZC como evolución de las prácticas de planificación y gobernanza territoriales. n. 9. Valencia: PUV/IIDL (Colección “Desarrollo Territorial”), 2011.

SCHERER, M.; SANCHES, M.; NEGREIROS, D. H. Gestão das zonas costeiras e as políticas públicas no Brasil: um diagnóstico. In: BARRAGÁN MUÑOZ, J. M. (coord.). Manejo Costero Integrado y Política Pública en Iberoamérica: Un diagnóstico. Necesidad de Cambio. Cádiz: Red IBERMAR (CYTED), p. 15-40, 2010.

SILVA, L. R. C. da et al. Pesquisa Documental: Alternativa investigativa na formação docente. In: IX Congresso Nacional de Educação EDUCERE. III Encontro Sul Brasileiro de Psicopedagogia. PUCPR, 26 a 29 out. 2009, p. 45-54.

SOUZA, C. Políticas Públicas: uma revisão da literatura. Sociologias, v. 8, n. 16, p. 20-45, 2006.

SOUZA, C. R. de G. A erosão Costeira e os Desafios da Gestão Costeira no Brasil. Revista de Gestão Costeira Integrada, v. 9, n. 1, p. 17-37, 2009.

SZLAFSZTEIN, C. F. Indefinições e Obstáculos no Gerenciamento da Zona Costeira do Estado do Pará, Brasil. Revista da Gestão Costeira Integrada, v. 9, n. 2, p. 47-58, 2009.

VASCONCELOS, F. P.; CORIOLANO, L. N. M. T. Impactos Sócio-Ambientais no Litoral: Um Foco no Turismo e na Gestão Integrada da Zona Costeira no Estado do Ceará/Brasil. Revista de Gestão Costeira Integrada, v. 8, n. 2, p. 259-275, 2008.

Artigo recebido em: 20/06/2018

Artigo aprovado em: 28/06/2018 